\title{
THE ISOLATION OF T-MYCOPLASMAS FROM THE UROGENITAL TRACT OF BULLS
}

\author{
D. TAYlor-Robinson*, M. Thomas* and P. L. Dawson $\dagger$ \\ * Clinical Research Centre, Harvard Hospital, Salisbury, and \\ $\dagger$ Hampshire Cattle Breeders' Society Limited, A.I. Centre, Lyndhurst, England
}

T-STRAIN mycoplasmas, hereafter referred to as T-mycoplasmas, have been isolated previously from the urogenital tract of cows and from the semen of a bull (Taylor-Robinson, Haig and Williams, 1967; Taylor-Robinson, Williams and Haig, 1968). These organisms have the same biological and physical characteristics as those first isolated by Shepard $(1954,1956)$ from the urogenital tract of man. Although they have been studied for a number of years, there is still doubt whether or not T-mycoplasmas are associated with disease. There are some workers (Ford, Rasmussen and Minken, 1962; Shepard et al., 1964; Csonka, Williams and Corse, 1966) who believe that they may be responsible for non-specific urethritis in males. Apart from providing information on their ecology, the study of T-mycoplasmas in other mammals may be of value not only in regard to disease in these animals, but indirectly in helping to assess pathogenicity in man. Because of these notions, we were stimulated to examine semen and material from various areas of the urogenital tracts of a larger number of bulls, our previous work having been confined almost exclusively to cows. Our finding that most bulls are infected by T-mycoplasmas suggests that the organisms have a commensal role in these animals.

\section{MATERIALS AND METHODS}

Semen samples. Semen from bulls was collected in sterile artificial vaginas, transferred to stoppered glass tubes and transported in crushed ice to the laboratory within $2 \mathrm{hr}$ of collection. The specimens were then kept at $4^{\circ} \mathrm{C}$ for up to $6 \mathrm{hr}$ before being examined.

Preputial cavity washings. Difco PPLO broth was contained in a pliable plastic bottle, to the end of which was attached a plastic tube. The tube was inserted into the preputial cavity and about $20 \mathrm{ml}$ of broth was introduced by compression of the bottle. After vigorous massage, about $10 \mathrm{ml}$ was returned to the bottle by decompression. The sample was treated subsequently in the same manner as semen.

Post-mortem specimens. Within a few minutes of death, the lower urogenital organs except the bladder were dissected free, placed in a plastic bag, and transported to the laboratory. The scrotal sac was seared briefly and opened, and the testicles were removed aseptically. From these, tissue was removed from mutiple sites, minced and placed in mycoplasma liquid medium. Fluid from the testicles was aspirated with a sterile pipette and also put into medium. Tissue from the vas deferens and prostate was treated similarly. The external aspect of the urethra was seared briefly and then the urethral canal was opened from above downwards and the mucosal lining scraped with the broken end of a glass pipette. The scrapings and expressed fluid were placed in medium. The lower portion of the preputial cavity was swabbed with a cottonwool swab which was broken off into medium.

Medium. Liquid medium consisted of Difco PPLO broth with 20 per cent. horse serum,

Received 10 Apr. 1969; accepted 14 May 1969.

J. MED. MICROBIOL.-VOL. 2 (1969) 
2.5 per cent. aqueous yeast extract, 0.1 per cent. urea and 0.002 per cent. phenol red. Penicillin (1000 units per $\mathrm{ml})$ and thallium acetate $(1$ in $4000 \mathrm{w} / \mathrm{v})$ were added as bacterial inhibitors. Solid medium was produced by the addition of 1 per cent. "Ionagar" no. 2 to the liquid medium. These media have been described in detail previously (Taylor-Robinson et al., 1968).

Isolation techniques. Liquid medium in $1.8-\mathrm{ml}$ amounts, contained in screw-capped glass vials of $2.5 \mathrm{ml}$ capacity, was seeded with $0.2 \mathrm{ml}$ of seminal fluid, etc., or a few pieces of minced tissue. The growth of T-mycoplasmas was observed as a colour change of the medium from yellow to red occurring on incubation at $37^{\circ} \mathrm{C}$. This " colour change" technique has been described in detail previously (Taylor-Robinson, Addey and Goodwin, $1969 a$ ). An estimate of the number of viable organisms present in a specimen was made by making serial 10-fold dilutions in the medium. The highest dilution of a specimen that produced a colour change contained one colour-changing unit $(\mathrm{CCU})$ of activity. In some instances, when a colour change was produced in liquid medium, $0.1 \mathrm{ml}$ of the culture was inoculated on solid medium; after incubation at $37^{\circ} \mathrm{C}$ for $1-2$ days, the solid medium was examined microscopically (magnification $\times 60-120$ ) for $\mathrm{T}$-mycoplasma colonies.

Identification of strains. Attempts to identify strains with rabbit antisera were made using the metabolic-inhibition technique (Purcell et al., 1966).

\section{RESULTS \\ Isolation of T-mycoplasmas from semen}

Bulls at A.I. Centre. As shown in table I, more colour changes were observed in the medium when the added semen samples were diluted 100- to 1000-fold

TABLE I

Isolation of T-mycoplasmas from the semen of 28 bulls

\begin{tabular}{c|c|c|c|c}
\hline $\begin{array}{c}\text { Semen diluted } \\
\text { in medium } \\
1 \text { in }\end{array}$ & \multicolumn{2}{|c|}{$\begin{array}{c}\text { No. of specimens giving a } \\
\text { colour-change reaction on } \\
\text { culture after the stated } \\
\text { period of incubation }\end{array}$} & $\begin{array}{c}\text { No. of } \\
\text { isolations }\end{array}$ \\
\hline 10 & 1 day & 2 days & 3 days & \\
\hline 100 & 1 & $2 *$ & 1 & $\begin{array}{r}2^{*} \\
1\end{array}$ \\
\hline Total & 0 & 14 & 1 & 5 \\
\hline
\end{tabular}

* These specimens may or may not have produced colour changes at higher dilutions also.

$\dagger$ On the day indicated, these specimens had not produced colour changes at the lower dilutions, although they may have done so after prolonged incubation.

than when the samples were diluted 10 -fold only. As soon as a colour change was observed, the medium was inoculated into fresh medium and, without exception, a further colour change was observed after incubation. Subculture from this liquid medium to solid medium was done in several instances and each time typical minute T-mycoplasma colonies were observed after incubation for $24-48 \mathrm{hr}$. On the other hand, subculture was not successful from those media that contained relatively high concentrations of semen but had not 
changed colour. In all, by such means, T-mycoplasmas were isolated from 23 seminal fluids of 28 bulls. Two ejaculates from one of the bulls were tested and the organisms were isolated from the second specimen only. Four other bulls were examined on more than one occasion and T-mycoplasmas were isolated each time. A semen sample which had been stored as a pellet in liquid nitrogen was also found to contain T-mycoplasmas.

Bulls on separate farms. As a result of relatively close contact and attention by the same handlers, bulls at the A.I. Centre might have become infected from each other. This would account for the high rate of isolation of mycoplasmas from these bulls and a similar incidence might not be observed among bulls less crowded together. To exclude this possibility, the semen of a bull on each of four separate farms was examined. T-mycoplasmas were isolated from all these specimens.

Large-colony-forming mycoplasmas were not found in any of the semen samples, but conditions for their detection were not optimal.

\section{Isolation of T-mycoplasmas from the preputial cavity}

Bulls at A.I. Centre. Washings from the preputial cavity of eight bulls were tested. Attempts to isolate T-mycoplasmas from seminal fluids of two of these bulls had failed. T-mycoplasmas were isolated from all of the washings. The specimens contained between $10^{5}$ and $10^{7}$ colour-changing units (CCU) per $\mathrm{ml}$ of washing. Low dilutions of the washings did not inhibit the development of colour changes.

Bulls on separate farms. Washings were collected from a bull on each of two separate farms. These specimens contained T-mycoplasma organisms in concentrations similar to those mentioned previously.

Preputial cavity washings from six steers were tested and T-mycoplasmas were isolated from two of these specimens.

Large-colony-forming mycoplasmas were detected in washings from two bulls, one at the A.I. Centre, but these mycoplasmas were not examined further.

\section{Isolation of T-mycoplasmas from unmated bulls}

Four bulls, three on separate farms, were stated not to have been in sexual contact with cows. T-mycoplasmas were isolated from all of them, from semen in two and from the preputial cavity in the others.

\section{Examination of urogenital tract after death}

Seminal and preputial washings were taken before the slaughter of two bulls, and preputial sac washings, urethral scrapings and specimens of the vas deferens and testicles were taken after slaughter from each of these bulls. All specimens were examined for T-mycoplasmas and the results are shown in table II. T-mycoplasmas were isolated from preputial cavity washings and seminal fluids only. 


\section{Attempt to serotype T-mycoplasmas}

Ten strains isolated from different bulls were tested by the metabolicinhibition technique with rabbit antisera that had been made against two bovine T-mycoplasmas, U8 and U20, described previously (Taylor-Robinson et al., 1968). One strain was inhibited by $U 20$ antiserum in dilutions up to the inhibitory titre for strain $\mathrm{U} 20$ and was thus regarded as probably identical with strain U20. Four strains were inhibited by a concentration of U20 antiserum that was four times greater than that required to inhibit the homologous

TABLE II

Isolation of T-mycoplasmas from bulls before and after slaughter

\begin{tabular}{|c|c|c|c|c|}
\hline \multirow{2}{*}{ Time of isolation } & \multirow{2}{*}{\multicolumn{2}{|c|}{ Specimen }} & \multicolumn{2}{|c|}{$\begin{array}{l}\text { No. of T-mycoplasmas* present } \\
\text { per ml of sample from }\end{array}$} \\
\hline & & & Bull 1 & Bull 2 \\
\hline Before slaughter & $\begin{array}{l}\text { Semen } \\
\text { Preputial cavity washing: }\end{array}$ & $: \quad:$ & $\geqq 10^{3}$ & $\geqq 10^{3}$ \\
\hline After slaughter & $\begin{array}{l}\text { Preputial cavity washing } \\
\text { Urethral mucosa scraping } \dagger \\
\text { Vas deferens tissue } \dagger \text {. } \\
\text { Testicular tissue } \dagger\end{array}$ & $: \quad:$ & $\begin{array}{l}\text { NT } \\
\text { NT } \\
\text { Nil } \\
\text { Nil }\end{array}$ & $\begin{array}{l}\geqq 103 \\
\text { Nil } \\
\text { Nil } \\
\text { Nil }\end{array}$ \\
\hline
\end{tabular}

organism, and were therefore only partially related to strain U20. One strain was partially inhibited by antisera to strains U20 and U8. Four strains were not inhibited by either antiserum.

\section{Inhibitor in seminal fluid}

An inhibitor of mycoplasma growth was demonstrable in some seminal fluids even when they were diluted 100 -fold (see table I). Seminal fluid from one bull (TWC) was centrifuged at 2000 r.p.m. for $10 \mathrm{~min}$. to remove spermatozoa. The supernatant fluid was then diluted in serial two-fold steps and each dilution mixed with $10^{6} \mathrm{CCU}$ of a bovine T-mycoplasma. Growth of the test mycoplasma was completely inhibited by a 1 in 80 dilution but not by a 1 in 160 dilution. The same activity was demonstrable after heating the fluid at $56^{\circ} \mathrm{C}$ for $30 \mathrm{~min}$. The inhibitor was found to be non-dialysable. In addition, serum from the same bull contained a non-dialysable, heat-stable factor that had similar inhibitory activity.

\section{Discussion}

The technique of isolation of T-mycoplasmas in liquid medium used in this study has been shown to be the most sensitive method for isolating these 
organisms (Taylor-Robinson et al., 1969a). We were surprised, nevertheless, that T-mycoplasmas were detected in specimens from so many of the bulls at the A.I. Centre. However, they were isolated also from apparently healthy bulls on several isolated farms and this suggests that the high isolation rate at the A.I. Centre was not spurious, i.e., due to close contact between animals, and that most bulls harbour the organisms.

We failed to isolate T-mycoplasmas from material taken from testicles, vas deferens, and the mucosal lining of the urethra soon after the death of two bulls, but we found the organisms in large numbers in the preputial cavity both before and after death. This suggests that the organisms gain access to seminal fluid from this site, "contamination" occurring at the time of ejaculation. The failure to isolate T-mycoplasmas from the urethral mucosa and other parts of the upper genital tract may be due to the presence of an inhibitor in bull semen. This substance is able to inhibit the growth of a high concentration of T-mycoplasma organisms. Furthermore, it appears that it is present in most seminal fluids: it was necessary to dilute most of the specimens of seminal fluid examined in the present investigation to reduce their inhibitory activity in order to recover the T-mycoplasmas. The exact nature of the inhibitor is unknown at present, but it is stable at $56^{\circ} \mathrm{C}$ and non-dialysable; it may be antibody. Inhibitory activity is not confined to semen since serum has similar properties.

The ecology of T-mycoplasmas in cattle, or man, is not fully clear. In man it seems likely that their major mode of spread from person to person involves sexual activity. They have been infrequently isolated from nuns (Archer, 1968) or from other persons before puberty (Csonka et al., 1966). However, the finding that a proportion of organisms remain viable after drying and also after mixing with a soap solution (Taylor-Robinson et al., 1969b) indicates that means of spread other than sexual are possible. Again, T-mycoplasmas may be present in the vagina of cows (Taylor-Robinson et al., 1968), but their presence in the preputial sacs of bulls is not necessarily due to sexual contact. These organisms were found in unmated bulls, and the youngest bull examined, one of $10 \mathrm{mth}$, harboured them. It is conceivable that they are present from birth, but we have no data on this point. In man, T-mycoplasmas have been isolated frequently from the urogenital tract and less frequently from the oropharynx (Ford, 1967; Purcell et al., 1967). In addition to their presence in the urogenital tract of cattle, T-mycoplasmas have been isolated from the lungs of cattle (Gourlay, 1968). The presence of T-mycoplasmas in high concentrations in the preputial sac and their stability on drying suggests that at least one mode of spread to the respiratory tract in cattle might be via contaminated fomites.

It is difficult to determine whether the T-mycoplasmas have a pathological role. It seems unlikely that their introduction into semen could play a significant part in decreasing the rate of conception among cows. Firstly, the semen inhibitor is likely to inactivate many of the organisms and secondly, the proportion of T-mycoplasma organisms to spermatozoa in seminal fluid is low. Over a period of $3 \mathrm{mth}$, the conception rate of cows given semen from the bulls 
tested in this study was similar to that of cows given semen from which Tmycoplasmas were not isolated. So far as the bulls are concerned, the presence of the organisms in large numbers in nearly all of the apparently healthy animals suggests that these mycoplasmas may be commensals only. However, on occasion, for example in the presence of a low concentration of semen inhibitor or in its absence, it is possible that T-mycoplasmas might ascend to other regions of the genital tract and evoke an inflammatory response. The experimental introduction of $\mathrm{T}$-mycoplasmas into the urogenital tracts of young pathogen-free bulls might provide an answer to this problem. Such experiments are in progress and this animal model might also help to throw light on the role of T-mycoplasmas in the urogenital tract of man.

\section{SUMMARY}

T-mycoplasmas were isolated from the semen of 23 of 28 bulls at an A.I. Centre, and from the semen of each of 4 bulls on separate farms. Washings from the preputial cavities of 10 bulls each contained at least $10^{5}$ organisms per $\mathrm{ml}$. In all, T-mycoplasmas were isolated from either semen or the preputial cavities of 28 of 34 bulls examined. Although the organisms were isolated from semen, they were not isolated from testicular tissue, the vas deferens or the mucosal scrapings of the urethra of 2 slaughtered bulls. It seems that the mycoplasmas are confined to the preputial cavity and gain access to semen during ejaculation. It is suggested that the failure of the organisms to become established in other areas of the genital tract is due to the presence of a potent mycoplasma inhibitor that was detected in bull semen in this study. A similar inhibitor was found in bull serum. It is thermostable at $56^{\circ} \mathrm{C}$ and nondialysable. The ecology and pathological role of the T-mycoplasmas in cattle are discussed in relation to the findings in man.

We thank Mr R. J. Manchee for help in some experiments, Miss Jean P. Addey and Mrs S. Beveridge for technical assistance, and $\mathrm{Mr} \mathrm{T}$. Moyle, Winchester abattoir, for assistance in obtaining post-mortem specimens.

\section{REFERENCES}

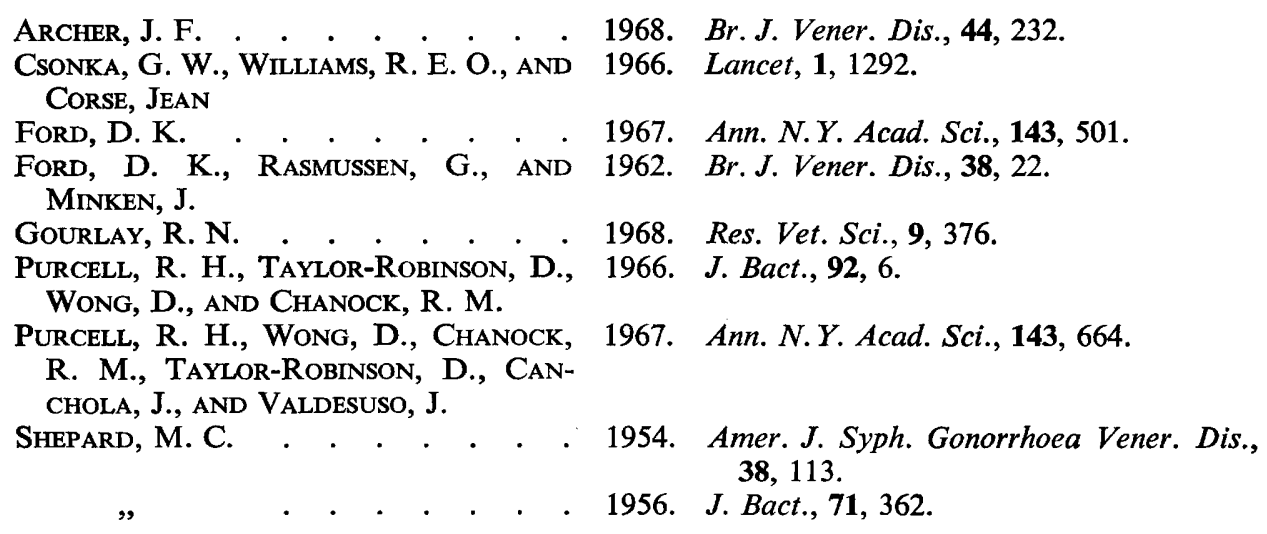


Shepard, M. C., AleXander, C. E., JR, 1964. J. Amer. Med. Assoc., 188, 729. LunCEFord, C. D., AND CAMPBell, P. E.

TAYlor-Robinson, D., Addey, Jean P., 1969a. Nature, Lond., 222, 274. AND GoODWIN, C. S.

Taylor-Robinson, D., Addey, Jean P., 1969b. Br. J. Vener. Dis., in press. Hare, M. J., AND Dunlop, E. M. C.

TAYlor-Robinson, D., Haig, D. A., ANd 1967. Ann. N.Y. Acad. Sci., 143, 517. WILLIAMS, M. H.

Taylor-Robinson, D., Williams, M. H., 1968. J. Gen. Microbiol., 54, 33. AND HAIG, D. A. 